Article

\title{
Reduction of Real-Time Imaging of M1 Macrophage Chemotaxis toward Damaged Muscle Cells is PI3K-Dependent
}

\author{
Hiromi Yano ${ }^{1, *}$, Masataka Uchida ${ }^{3}$, Tatsuya Saito ${ }^{1}$, Takafumi Aoki ${ }^{2}$, Michael J. Kremenik ${ }^{1}$ and \\ Eri Oyanagi 1 \\ 1 Department of Health \& Sports Science, Kawasaki University of Medical Welfare, 288 Matsushima \\ Kurashiki, Okayama 701-0193, Japan; t.saito@mw.kawasaki-m.ac.jp (T.S.); \\ kremelin@mw.kawasaki-m.ac.jp (M.J.K.); eri-oyanagi@mw.kawasaki-m.ac.jp (E.O.) \\ 2 Graduate School of Health Science and Technology, Kawasaki University of Medical Welfare, \\ Okayama 701-0193, Japan; aoki.takafumi.54331@mw.kawasaki-m.ac.jp \\ 3 Faculty of Sport and Health Science, Ritsumeikan University, Shiga 525-8577, Japan; \\ m-uchida@fc.ritsumei.ac.jp \\ * Correspondence: yanohiro@mw.kawasaki-m.ac.jp; Tel.: +81-86-462-1111; Fax: +81-86-464-1109
}

Received: 7 August 2018; Accepted: 4 October 2018; Published: 8 October 2018

\begin{abstract}
Macrophages migrate and invade into damaged muscle rapidly and are important for muscle repair and subsequent regeneration. The exact cellular and biological events that cause macrophage migration toward injured muscle are not completely understood. In this study, the effect of macrophage differentiation on the chemotactic capability to invade local damaged muscle was investigated using an in vitro model of muscle injury. We used C2C12 cell myoblasts and J774 cell macrophages, and the "killed-C2C12" cells were combined with live C2C12 cells as a partially damaged muscle model. The cultured J774 cells, with or without lipopolysaccharide (LPS), were treated with Ly294002 (Ly), which is an inhibitor of phosphoinositide 3-kinase (PI3K). In order to evaluate the polarization effect of LPS stimulation on J774 cells, expression of cell surface Toll-like receptor 4 (TLR4), CD11c and CCR2, and expression of F-actin intensity, were analyzed by flow cytometry. The real-time horizontal chemotaxis assay of J774 cells was tested using the TAXIScan device. The expressions of TLR4, CD11c, and F-actin intensity in LPS-treated cells were significantly higher than those in Ctrl cells. In LPS-treated cells, the chemotactic activity toward damaged muscle cells completely disappeared. Moreover, the reduced chemotaxis depended far more on directionality than velocity. However, Ly treatment reversed the reduced chemotactic activity of the LPS-treated cells. In addition, cell-adhesion and F-actin intensity, but not CCR2 expression, in LPS-treated cells, was significantly reduced by Ly treatment. Taken together, our results suggest that the PI3K/Akt activation state drives migration behavior towards damaged muscle cells.
\end{abstract}

Keywords: J774; C2C12; TAXIScan; lipopolysaccharide; Ly294002

\section{Introduction}

It is known that macrophages as well as neutrophils migrate and infiltrate into the location of damaged muscle [1-3]. This immunological response is considered to be important for muscle repair and subsequent regeneration [4-9].

The phenotype of macrophages, which display different functional features, influences chemotaxis [10]. Macrophage phenotypes were classified into two groups: Classically activated macrophages (M1) and alternatively activated macrophages (M2), which are further divided into groups M2a, M2b and M2c [11]. Although lipopolysaccharide (LPS), which strongly induces 
differentiation into inflammatory macrophages such as M1, also affects macrophage motility, the effects of macrophage differentiation on chemotaxis toward damaged muscle has been poorly understood.

Kleveta et al. (2012) [12] showed that F-actin expression was upregulated by LPS treatment, and moreover, we reported that LPS-treated macrophages were accompanied by both a high F-actin expression with a low expression of CCR2 (a receptor for monocyte chemoattractant protein-1) and a decrease in chemotactic activity [13]. Therefore, macrophage differentiation strongly influenced the chemotactic activity toward damaged myoblast cells through the expression of F-actin [13] and CCR2 [13,14].

Inflammation, such as that induced by LPS stimulation, upregulates the phosphoinositide 3-kinase (PI3K)/Akt signaling pathway $[15,16]$. In addition, the possible relevance of mTOR/S6K, which is present downstream of the PI3K/Akt signaling pathway, in neutrophil migration, has been shown [17]. The important role of the PI3K/Akt signaling pathway in the regulation of stress fiber formation and cell migration is already known [18-20]. Moreover, activation of the PI3K/Akt signaling pathway is essential for macrophage migration [21], as well as other migratory cells. Hence, when cells need to negatively regulate migration, F-actin remodeling up-regulates and cell adhesion increases. A recent report showed that, with LPS stimulation, one of the Rab family of small GTPases recruits PI3K, which regulates Akt signaling generated by surface Toll-like receptor 4 (TLR4) on macrophages, and then regulates mTOR signaling in macrophages [22]. It seems that this signal pathway regulates multiple steps of membrane trafficking and phagocytosis of pathogens [22]. However, it remains unclear whether LPS-induced PI3K activation is associated with inflammatory macrophage chemotaxis toward damaged muscle cells.

In this study, we investigated the effect of macrophage differentiation on the real-time imaging of inflammatory macrophage chemotaxis toward damaged muscle cells. Our hypothesis was that macrophage chemotaxis toward damaged muscle cells influences their differentiation through the activation of PI3K.

\section{Materials and Methods}

\subsection{Reagents}

Lipopolysaccharide (Escherichia coli 055:B5) and Ly294002 (Ly) were purchased from Sigma (St Louis, MO, USA).

\subsection{Cell Culture}

Mouse myoblasts cell line C2C12 cells and mouse macrophage cell line J774 cells were purchased from the Cell Bank Riken Bioresource Center (Ibaraki, Japan). These cells were grown in a 10-cm dish with Dulbecco's Modified Eagle's medium containing 10\% heat-inactivated FCS, added with $200 \mathrm{U} / \mathrm{mL}$ penicillin and $100 \mu \mathrm{g} / \mathrm{mL}$ streptomycin, at $37^{\circ} \mathrm{C}$ in $5 \% \mathrm{CO}_{2}$.

In all experiments, the $\mathrm{C} 2 \mathrm{C} 12$ cells were switched to a 6- or a 96-well flat-bottomed cell culture plate after they reached the myoblast stage. The medium was changed the day after seeding and each second day thereafter. The $\mathrm{C} 2 \mathrm{C} 12$ cells were used from passage 2 to 10 . The killed-C2C12 cells were induced by repeat freezing (three times) by liquid nitrogen for $60 \mathrm{sec}$ and incubation at $37^{\circ} \mathrm{C}$ for $3 \mathrm{~min}$, and then they were combined with live $\mathrm{C} 2 \mathrm{C} 12$ at 1:0.5 (live:killed $\mathrm{C} 2 \mathrm{C} 12$ ) as a partially damaged muscle model [13].

J774 cells were stimulated by $100 \mathrm{ng} / \mathrm{mL}$ LPS with or without $20 \mu \mathrm{M}$ Ly for $24 \mathrm{~h}$. The cells' polarization was evaluated by the expression of surface TLR4 and CD11c using flow cytometry. Moreover, to evaluate M1 activation status, the concentration of tumor-necrosis factor (TNF)- $\alpha$ in the cells-conditioned medium sample was measured $24 \mathrm{~h}$ after the stimulation. 


\subsection{Real Time Horizontal Chemotaxis Assay Using TAXIScan}

Chemotaxis assays of J774 cells were carried out using the TAXIScan device (ECI, Tokyo, Japan) $[13,23,24]$. Migration of $\mathrm{J774}$ cells at $37^{\circ} \mathrm{C}$ was recorded every $3 \mathrm{~min}$. The migrating cells were traced by clicking each cell on the display and the average values of parameters were calculated. The data were from three independent observers. The velocity of cell migration is expressed $\mu \mathrm{m} / \mathrm{s}$. The directionality of migration is expressed as the angle (radian) toward the opposite compartment (i.e., $\pi / 2$ indicates that the $\mathrm{J} 774$ cell is migrating toward the $\mathrm{C} 2 \mathrm{C} 12$ cells).

\subsubsection{Flow Cytometric Analysis}

The expression of surface TLR4, CD11c and CCR2 on each macrophage was measured by flow cytometric analysis. Briefly, the cells $\left(2 \times 10^{5}\right.$ cells) were treated with FcR blocker (mouse normal serum, Biomeda, Foster City, CA, USA) for $30 \mathrm{~min}$ on ice, and then stained in ice-cold PBS containing $0.3 \% \mathrm{BSA}$ and $0.05 \% \mathrm{NaN}_{3}$ with the following antibodies: Anti-TLR4-PE, anti-CD11c-FITC and isotype controls (BD Bioscience, San Diego, CA, USA), and CCR2 (anti-mouse CCR2 rabbit polyclonal antibody, Abcam, Cambridge, UK). F-actin was stained by phalloidin (Acti-stain ${ }^{\mathrm{TM}} 555$ phalloidin, Cytoskeleton, Denver, CO, USA). The flow cytometric analysis was performed using the FACSCalliber ${ }^{\mathrm{TM}}$ Flow Cytometry System with the CellQuest software package (BD, Franklin Lakes, NJ, USA). The change in the mean fluorescence intensity (MFI) between anti-TLR4 and CD11c antibodies and each isotype control were obtained to quantify the expression of each marker.

\subsubsection{Adherence to Plastic}

J774 cells $\left(2 \times 10^{5}\right)$ were seeded into untreated plastic flat-bottomed (96-well) plate and incubated at $37^{\circ} \mathrm{C}$ for $60 \mathrm{~min}$. Then, we removed the non-adherent cells and then fixed the remaining cells with $2 \%$ glutaraldehyde for $10 \mathrm{~min}$. The cells were stained with $0.5 \%$ crystal violet in $200 \mathrm{mM}$ boric acid for 15 min after wells were washed twice with $\mathrm{H}_{2} \mathrm{O}$. After they were washed three times, the cells were lysed by $10 \%$ acetic acid and measured OD by $560 \mathrm{~nm}$.

\subsubsection{Western Blot Analysis}

Cells, which were washed in PBS, were lysed by RIPA buffer with a protease inhibitor cocktail (25955-11, Nacalai Tesque, Tokyo, Japan), and then their protein concentrations were measured by Bradford assay (Bio-Rad, Hercules, CA, USA). Equal amounts of extracts were separated by $10 \%$ SDS-PAGE, and then were transferred onto a nitrocellulose membrane, which was probed with primary antibodies overnight at $4{ }^{\circ} \mathrm{C}$. After incubation with HRP-conjugated secondary antibodies at room temperature for $60 \mathrm{~min}$, the target proteins were detected with a chemiluminescence kit (Chemi-Lumi One Super, 02230, Nacalai Tesque), and quantified with Amersham Imager 600 (GE Health Care, Chalfont St. Giles, UK). Primary antibodies used include those against Akt (\#9272, 1:1000), phospho-Akt (\#9275, 1:1000) and GAPDH (\#2118, 1:10,000) from Cell Signaling Technology (Danvers, MA, USA), which was used as an internal control.

\subsubsection{Enzyme-Linked Immunosorbent Assay (ELISA)}

The concentration of TNF- $\alpha$ was measured by ELISA (a murine and human kit, R\&D Systems, Minneapolis, MN, USA). The absorbance was measured at $450 \mathrm{~nm}$ and was proportional to the concentration of TNF- $\alpha$ in the sample.

\subsection{Statistical Analysis}

Data were expressed as mean \pm SEM. Statistical calculations were carried out with the SPSS 15.0 for Windows software program. The data were analyzed using the one-way analysis of variance (ANOVA). Bonferroni's tests were performed as post-hoc. A p-value less than $5 \%$ was considered statistically significant. 


\section{Results}

\subsection{Effect of Ly Treatment on LPS-Induced Differentiation on the Macrophages}

The cell-surface expression of TLR4 and CD11c on J774 cells after LPS and/or Ly treatments are shown in Figure 1. Expressions of TLR4 and CD11c on cell surface in both LPS- and LPS+Ly-treated cells were significantly higher than that in Ctrl cells $(p<0.01$, Figure $1 C$ and D). Although the expression level of TLR4 between LPS and LPS+Ly cells showed no significant difference (Figure 1C), CD11c expression on LPS+Ly cells was significantly lower than that on the LPS cells $(p<0.01$, Figure 1D).
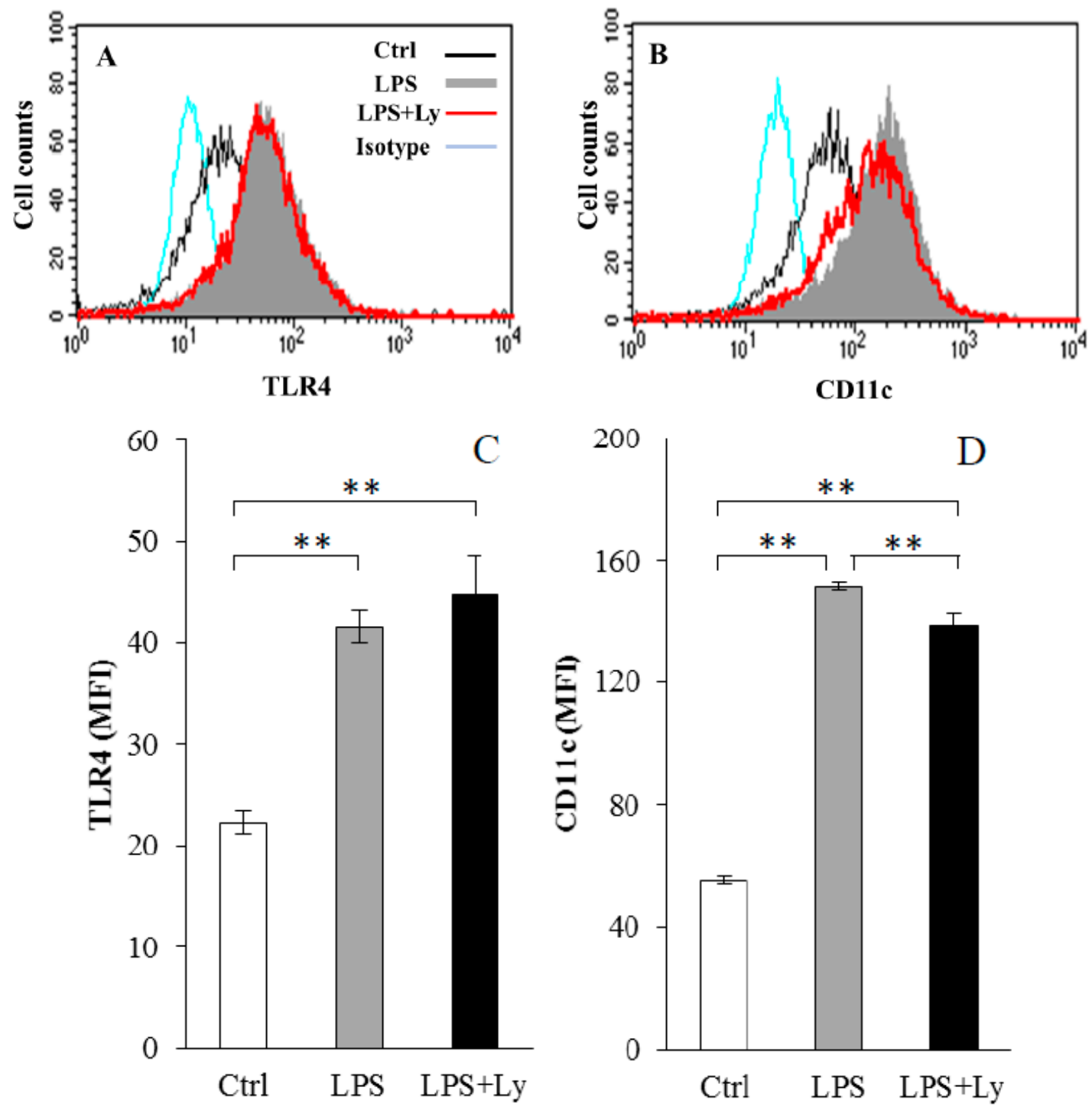

Figure 1. The cell-surface expression of Toll-like receptor 4 (TLR4) (A,C) and CD11c (B,D) on J774 cells after lipopolysaccharide (LPS) and/or Ly treatments. Typical data (A,B) and MFI (the mean \pm SEM $(\mathbf{C}, \mathbf{D}))$ of LPS and LPS+Ly treated J774 cells are shown $(n=6) .{ }^{* *} p<0.01$.

\subsection{Effect of Ly Treatment on LPS-Induced Differentiation in the Macrophages}

Cell adherence, which was significantly increased by LPS stimulation $(p<0.01$, vs. Ctrl cells), was strongly inhibited by Ly treatment $(p<0.01$, vs. LPS cells, Figure 2A). F-actin intensity also had the same result as cell adherence (Figure 2B). However, the influence of LPS and Ly stimulation on CCR2 expression was not observed (Figure 2C). 
A

B

$\mathrm{C}$
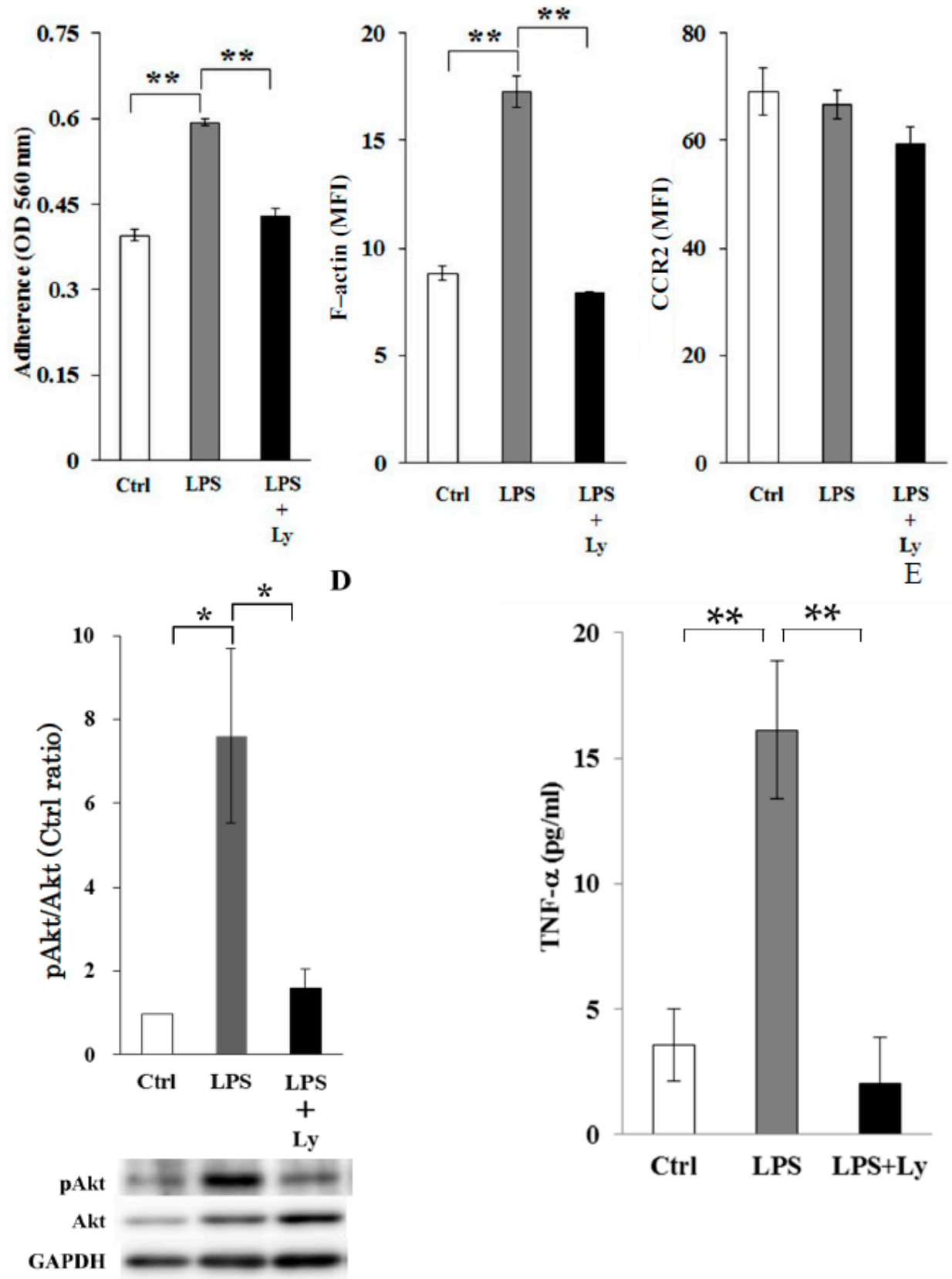

Figure 2. The effect of phosphoinositide 3-kinase (PI3K) inhibitor Ly treatments on cell adherence (A), F-actin (B), CCR2 (C), phosphorylation of Akt proteins (D) and TNF- $\alpha$ production (E) of J774 cells $(n=8) .{ }^{*} p<0.05$ and ${ }^{* *} p<0.01$. Western blot results of phospho-Akt (pAkt)/total Akt. Results were quantitated by densitometry and ratios of pAkt/total Akt were plotted. Y axis is in arbitrary unit (D).

The high level of phosphorylation of Akt (pAkt)/total Akt seen in LPS treated cells $(p<0.05$, vs. Ctrl cells) was significantly inhibited by Ly treatment $(p<0.05$, Figure 2D). Additionally, increasing TNF- $\alpha$ production in LPS-treated cells was also inhibited by Ly treatment $(p<0.01$, Figure 2E).

\subsection{Effect of Ly Treatment on LPS-Induced Differentiation on the Cells Chemotactic Activity}

Direct comparison of 5 frames from the video (Video S1) with equivalent frames from the chemotaxis of macrophages toward damaged C2C12 cells is shown in Figure 3. Although chemotaxis of Ctrl cells toward damaged C2C12 cells was observed, that of LPS-treated cells disappeared completely. 
However, this disappearance of chemotaxis was not observed in the case of LPS+Ly-treated cells. Moreover, in this experiment, chemotaxis of macrophages was evaluated in each directionality and velocity (Figure 4). The directionality of LPS-treated cells toward C2C12 cells was significantly lower than that of both Ctrl and LPS+Ly cells ( $p<0.01$, respectively), and then the directionality of LPS+Ly cells is slightly, but significantly, higher than that of Ctrl cells $(p<0.05$, Figure $4 \mathrm{~A})$. On the other hand, the velocity was not different between LPS+Ly and LPS cells, although the velocity of both LPS+Ly and LPS cells was significantly higher than that of Ctrl cells ( $p<0.01$, respectively, Figure 4B).
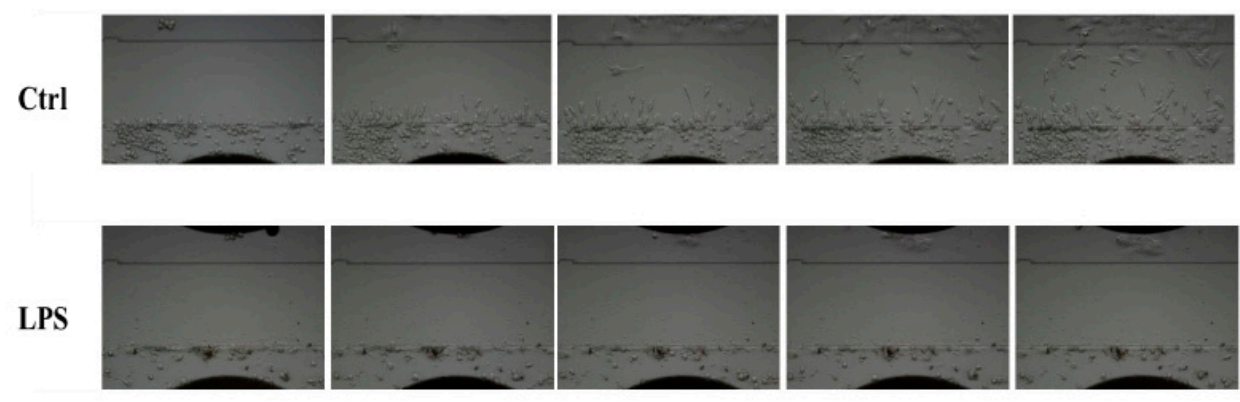

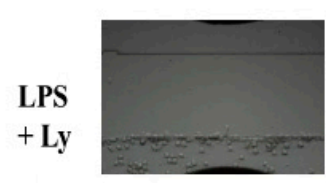

0

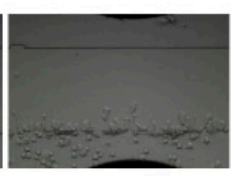

2.5

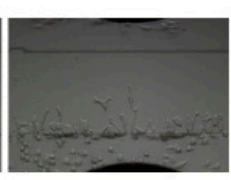

5

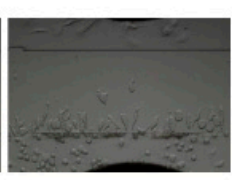

7.5

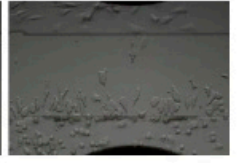

10 (h)

Figure 3. Direct comparison of 5 frames from the video (selected frames in order from $0 \mathrm{~h}$ to $10 \mathrm{~h}$ ) with equivalent frames from the chemotaxis of macrophages toward damaged C2C12 cells.

A

B
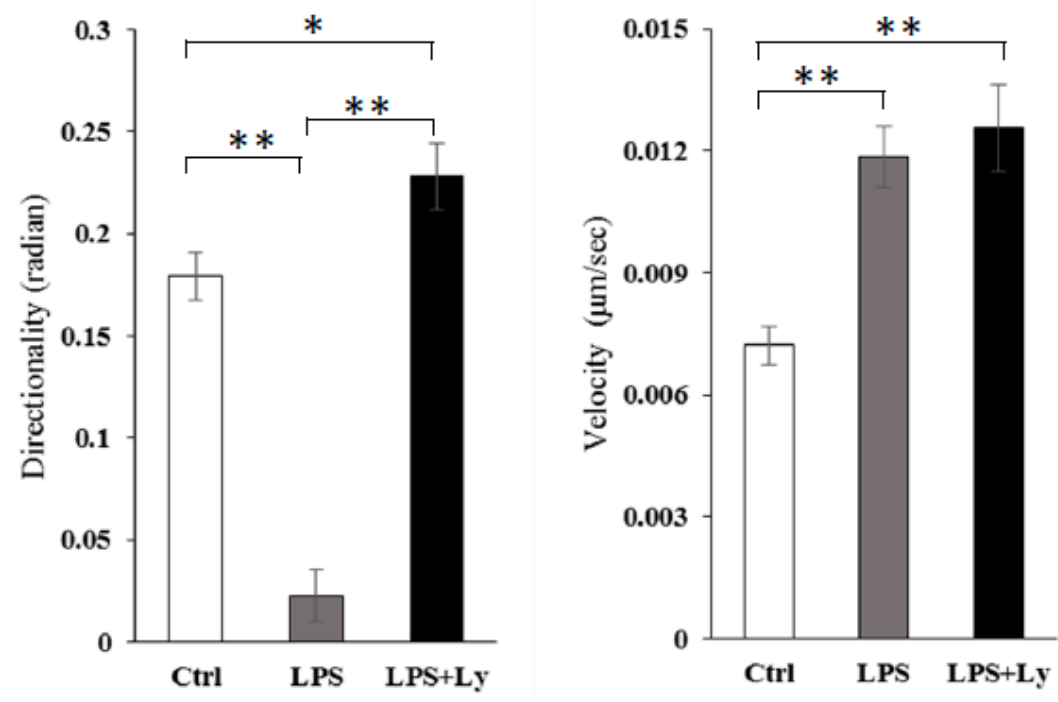

Figure 4. Chemotaxis, shown as directionality (A) and velocity (B), of J774 cells toward damaged C2C12 cells ( $n=100$ for each condition). ${ }^{*} p<0.05$ and ${ }^{* *} p<0.01$.

\section{Discussion}

This study demonstrates that LPS-inhibited macrophage chemotaxis to invade local damaged muscle is associated with F-actin expression, and the inhibition of macrophage chemotaxis was completely reversed by the PI3K inhibitor. These findings suggest that macrophage chemotaxis toward damaged muscle depends on their differentiation through the activation of PI3K. 
In this study, a directed migration experiment was performed using a TAXIScan device assay. TAXIScan is an assay device for studying cell dynamics in vitro, which functions by providing two-dimensional images of cell migration. Accordingly, this device can provide markedly more information, including morphology as well as quantitative analysis, compared to existing methods such as the Boyden chamber method [13,24-26]. Interestingly, the directionality and velocity of chemotactic cells can be provided by analyzing the cell images. In fact, we observed that the directionality of J774 cells toward damaged muscle cells was inhibited by LPS treatment, and that it was completely rescued by Ly treatment. In contrast, the velocity of J774 cells was not different between LPS and LPS+Ly cells. A previous study reported that the chemotactic activity of M1 macrophages to damaged skeletal muscle cells is lower than that of M2 macrophages, which is more directionally dependent than velocity [13]. Expressions of $C d 11 c$ and Tlr4 mRNA as markers of pro-inflammatory M1 macrophages have been demonstrated [24,27]. Thus, our results are strongly supported by this previous study. In addition, Uchida et al. (2013) [13] suggested that the low chemotactic activity of M1 macrophages toward damaged muscle cells is associated with a high expression of F-actin and a low expression of CCR2. F-actin expression is upregulated by LPS treatment [4]. Moreover, it was shown that the distribution of F-actin in LPS-treated cells was observed strongly around the cell membrane, when the expression of F-actin in macrophages was increased by LPS stimulation [13]. Since F-actin remodeling has an essential function in cell movement and cell adhesion [28], we tried to examine the influence of F-actin expression in LPS-treated macrophage chemotaxis. As for the results, Ly treatment inhibited LPS-induced F-actin expression when the reduced chemotaxis of macrophages was rescued by the Ly treatment. LPS stimulates the PI3K/Akt signal, up-regulates F-actin remodeling and also increases cell adhesion [11]. Moreover, it has been suggested that TLR4 signaling involves PI3K activation [11]. Therefore, movement in one direction, such as the direction toward damaged myoblast cells, might be limited by F-actin remodeling, which is induced by the LPS/TLR4-PI3K/Akt pathway.

On the other hand, chemokines are the major mediators of macrophage chemotaxis via chemokine receptors. The low chemotactic activity of M1 macrophages toward damaged muscle cells might be associated with expression of CCR2. However, in the present study, the influence of LPS and Ly stimulation on CCR2 expression on macrophages was not observed, although chemotaxis was greatly different between LPS and LPS+Ly stimulations. Also, in previous studies, LPS induced a reduction [29,30], no effect [25] or an increase [26] in CCR2. This discrepancy might be attributable to different assay conditions or cells used. Thus, the matching results are not shown. At least, our results strongly suggest that macrophage chemotaxis toward damaged muscle depends on their degree of F-actin remodeling through the activation of PI3K. It seems that M1 macrophages are thought to migrate over shorter distances compared with M2 macrophages. Our previous study, and other studies, showed that M2 macrophages, compared to M1 macrophages, displayed enhanced motility towards damaged muscle cells and chemokines (CCL2, CXCL12 and C1q), respectively [13,25].

Our study has limitations. Firstly, LPS+Ly macrophages showed constant expression of TLR4 and CD11c, which are M1 macrophage markers, on the cell surface. However, PI3K inhibition by Ly treatment results in a robust reduction of TNF-alpha release. Therefore, it is possible that LPS+Ly macrophages are no longer of the M1 phenotype. In fact, it was already reported that Ly treatment induces suppression of TNF- $\alpha$ secretion $[15,16]$. Although a high expression of CCR2 on the cell surface of M2 cells is known [13], the PI3K inhibitor did not affect the CCR2 expression on the LPS-treated cells. Furthermore, a recent study suggested that CCR2 on macrophages was associated with M1-phenotype switching in addition to cell migration [31]. In our study, the CCR2 expression showed no significant difference between LPS and LPS+Ly macrophages. Because PI3K exists as an upstream event of the NF- $\mathrm{kB}$ pathway, which is the important downstream pathway mediated by TLR4 [15,16], PI3K inhibitor Ly treatment induced this paradoxical phenomena, which means that it inhibited TNF- $\alpha$ secretion despite constant expression of TLR4 and CD11c on the cell surface. 
Secondly, this study cannot answer the point, which Perdiguero et al. (2011) [32] made, that the PI3K/Akt inhibitor disturbs normal macrophage cell behavior in injured muscle over time and could also delay cytokine silencing during the resolution of inflammation. Therefore, further study is needed as to whether regulation of inflammation-mediated tissue repair is possible by continuously controlling PI3K/Akt activation.

In conclusion, we investigated the effect of macrophage differentiation on the real-time imaging of inflammatory macrophage chemotaxis toward damaged muscle cells. Our results suggest that the PI3K/Akt activation state drives migration behavior towards damaged muscle cells.

Supplementary Materials: The following are available online at http:/ / www.mdpi.com/2076-3921/7/10/138/s1, Video S1: A video showing the macrophages chemotaxis toward C2C12 cells (live:killed cells = 1:0.5). Ctrl: unstimulated-J774 cells, LPS: LPS-treated J774 cells and LPS+Ly: Ly treated LPS-J774 cells. In each picture, C2C12 and J774 cells seeded on the upper and the lower compartments, respectively.

Author Contributions: H.Y. was involved in acquisition of data, data analysis, data interpretation and writing of the manuscript. T.S. and T.A. performed both data acquisition and analysis. M.J.K. was involved in data interpretation and writing of the manuscript. M.U. and E.O. participated in study design, conceptualization, data analysis and helped to draft the manuscript. All authors read and approved the final manuscript.

Funding: This research was funded by [Japan Society for the Promotion of Science] grant number [C-24500878] and [15H03102] and [Interdepartmental Research Fund of Kawasaki University of Medical Welfare] grant number [15-D].

Acknowledgments: We thank the staff of the Molecular Cell Biology Research Unit and Bio-Imaging Research Unit at Kawasaki Medical School.

Conflicts of Interest: The authors declare no conflicts of interest.

\section{References}

1. Tidball, J.G.; Berchenko, E.; Frenette, J. Macrophage Invasion does not Contribute to Muscle Membrane Injury during Inflammation. J. Leukoc. Biol. 1999, 65, 492-498. [CrossRef] [PubMed]

2. Nguyen, H.X.; Tidball, J.G. Interactions between neutrophils and macrophages promote macrophage killing of rat muscle cells in vitro. J. Physiol. 2003, 547, 125-132. [CrossRef] [PubMed]

3. Peake, J.M.; Neubauer, O.; Della Gatta, P.A.; Nosaka, K. Muscle Damage and Inflammation during Recovery from Exercise. J. Appl. Physiol. 2017, 122, 559-570. [CrossRef] [PubMed]

4. Tidball, J.G.; Villalta, S.A. Regulatory Interactions between Muscle and the Immune System during Muscle Regeneration. Am. J. Physiol. Regul. Integr. Comp. Physiol. 2010, 298, R1173-R1187. [CrossRef] [PubMed]

5. Peake, J.; Della Gatta, P.; Cameron-Smith, D. Aging and Its Effects on Inflammation in Skeletal Muscle at Rest and Following Exercise-Induced Muscle Injury. Am. J. Physiol. Regul. Integr. Comp. Physiol. 2010, 298, R1485-R1495. [CrossRef] [PubMed]

6. Rigamonti, E.; Zordan, P.; Sciorati, C.; Rovere-Querini, P.; Brunelli, S. Macrophage Plasticity in Skeletal Muscle Repair. BioMed Res. Int. 2014. [CrossRef] [PubMed]

7. Juban, G.; Chazaud, B. Metabolic Regulation of Macrophages during Tissue Repair: Insights from Skeletal Muscle Regeneration. FEBS Lett. 2017, 591, 3007-3021. [CrossRef] [PubMed]

8. Arnold, L.; Henry, A.; Poron, F.; Baba-Amer, Y.; van Rooijen, N.; Plonquet, A.; Gherardi, R.K.; Chazaud, B. Inflammatory monocytes recruited after skeletal muscle injury switch into antiinflammatory macrophages to support myogenesis. J. Exp. Med. 2007, 204, 1057-1069. [CrossRef] [PubMed]

9. Wang, H.; Melton, D.W.; Porter, L.; Sarwar, Z.U.; McManus, L.M.; Shireman, P.K. Altered Macrophage Phenotype Transition Impairs Skeletal Muscle Regeneration. Am. J. Pathol. 2014, 184, 1167-1184. [CrossRef] [PubMed]

10. Xuan, W.; Qu, Q.; Zheng, B.; Xiong, S.; Fan, G.H. The Chemotaxis of M1 and M2 Macrophages is Regulated by Different Chemokines. J. Leukoc. Biol. 2015, 97, 61-69. [CrossRef] [PubMed]

11. Martinez, F.O.; Gordon, S. The M1 and M2 Paradigm of Macrophage Activation: Time for Reassessment. F1000Prime Rep. 2014, 6, 13. [CrossRef] [PubMed]

12. Kleveta, G.; Borzęcka, K.; Zdioruk, M.; Czerkies, M.; Kuberczyk, H.; Sybirna, N.; Sobota, A.; Kwiatkowska, K. LPS Induces Phosphorylation of Actin-Regulatory Proteins Leading to Actin Reassembly and Macrophage Motility. J. Cell Biochem. 2012, 113, 80-92. [CrossRef] [PubMed] 
13. Uchida, M.; Oyanagi, E.; Miyachi, M.; Yamauchi, A.; Yano, H. Relationship between Macrophage Differentiation and the Chemotactic Activity toward Damaged Myoblast Cells. J. Immunol. Methods 2013, 393, 61-69. [CrossRef] [PubMed]

14. Lu, H.; Huang, D.; Saederup, N.; Charo, I.F.; Ransohoff, R.M.; Zhou, L. Macrophages Recruited via CCR2 Produce Insulin-Like Growth Factor-1 to Repair Acute Skeletal Muscle Injury. FASEB J. 2011, 25, 358-369. [CrossRef] [PubMed]

15. Eräsalo, H.; Laavola, M.; Hämäläinen, M.; Leppänen, T.; Nieminen, R.; Moilanen, E. PI3K Inhibitors LY294002 and IC87114 Reduce Inflammation in Carrageenan-Induced Paw Oedema and Down-Regulate Inflammatory Gene Expression in Activated Macrophages. Basic Clin. Pharmacol. Toxicol. 2015, 116, 53-61. [CrossRef] [PubMed]

16. Li, C.; Zhao, B.; Lin, C.; Gong, Z.; An, X. TREM2 Inhibits Inflammatory Responses in Mouse Microglia by Suppressing the PI3K/NF-kB Signaling. Cell Biol. Int. 2018. [CrossRef] [PubMed]

17. Gomez-Cambronero, J. Rapamycin Inhibits GM-CSF-Induced Neutrophil Migration. FEBS Lett. 2003, 550, 94-100. [CrossRef]

18. Fukata, M.; Nakagawa, M.; Kaibuchi, K. Roles of Rho-Family GTPases in Cell Polarisation and Directional Migration. Curr. Opin. Cell Biol. 2003, 15, 590-597. [CrossRef]

19. Raftopoulou, M.; Hall, A. Cell Migration: Rho GTPases Lead the Way. Dev. Biol. 2004, 265, 23-32. [CrossRef] [PubMed]

20. Jaffe, A.B.; Hall, A. Rho GTPases: Biochemistry and biology. Annu. Rev. Cell Dev. Biol. 2005, 21, $247-269$. [CrossRef] [PubMed]

21. Don, M.J.; Liao, J.F.; Lin, L.Y.; Chiou, W.F. Cryptotanshinone Inhibits Chemotactic Migration in Macrophages through Negative Regulation of the PI3K Signaling Pathway. Br. J. Pharmacol. 2007, 151, 638-646. [CrossRef] [PubMed]

22. Luo, L.; Wall, A.A.; Yeo, J.C.; Condon, N.D.; Norwood, S.J.; Schoenwaelder, S.; Chen, K.W.; Jackson, S.; Jenkins, B.J.; Hartland, E.L.; et al. Rab8a Interacts Directly with PI3K $\gamma$ to Modulate TLR4-Driven PI3K and mTOR Signalling. Nat. Commun. 2014, 5, 4407. [CrossRef] [PubMed]

23. Nitta, N.; Tsuchiya, T.; Yamauchi, A.; Tamatani, T.; Kanegasaki, S. Quantitative Analysis of Eosinophil Chemotaxis Tracked Using a Novel Optical Device-TAXIScan. J. Immunol. Methods 2007, 320, 155-163. [CrossRef] [PubMed]

24. Ito, A.; Suganami, T.; Yamauchi, A.; Degawa-Yamauchi, M.; Tanaka, M.; Kouyama, R.; Kobayashi, Y.; Nitta, N.; Yasuda, K.; Hirata, Y.; et al. Role of CC Chemokine Receptor 2 in Bone Marrow Cells in the Recruitment of Macrophages into Obese Adipose Tissue. J. Biol. Chem. 2008, 283, 35715-35723. [CrossRef] [PubMed]

25. Vogel, D.Y.; Heijnen, P.D.; Breur, M.; de Vries, H.E.; Tool, A.T.; Amor, S.; Dijkstra, C.D. Macrophages Migrate in an Activation-Dependent Manner to Chemokines Involved in Neuroinflammation. J. Neuroinflamm. 2014, 11, 23. [CrossRef] [PubMed]

26. Yamauchi, A.; Yamamura, M.; Katase, N.; Itadani, M.; Okada, N.; Kobiki, K.; Nakamura, M.; Yamaguchi, Y.; Kuribayashi, F. Evaluation of Pancreatic Cancer Cell Migration with Multiple Parameters in Vitro by Using an Optical Real-Time Cell Mobility Assay Device. BMC Cancer 2017, 17, 234. [CrossRef] [PubMed]

27. Kawanishi, N.; Yano, H.; Yokogawa, Y.; Suzuki, K. Exercise Training Inhibits Inflammation in Adipose Tissue via Both Suppression of Macrophage Infiltration and Acceleration of Phenotypic Switching from M1 to M2 Macrophages in High-Fat-Diet-Induced Obese Mice. Exerc. Immunol. Rev. 2010, 16, 105-118. [PubMed]

28. Bugyi, B.; Carlier, M.F. Control of Actin Filament Treadmilling in Cell Motility. Annu. Rev. Biophys. 2010, 39, 449-470. [CrossRef] [PubMed]

29. Xu, L.; Rahimpour, R.; Ran, L.; Kong, C.; Biragyn, A.; Andrews, J.; Devries, M.; Wang, J.M.; Kelvin, D.J. Regulation of CCR2 Chemokine Receptor mRNA Stability. J. Leukoc. Biol. 1997, 62, 653-660. [CrossRef] [PubMed]

30. Rowley, S.M.; Kuriakose, T.; Dockery, L.M.; Tran-Ngyuen, T.; Gingerich, A.D.; Wei, L.; Watford, W.T. Tumor Progression Locus 2 (Tpl2) Kinase Promotes Chemokine Receptor Expression and Macrophage Migration during Acute Inflammation. J. Biol. Chem. 2014, 289, 15788-15797. [CrossRef] [PubMed] 
31. Deci, M.B.; Ferguson, S.W.; Scatigno, S.L.; Nguyen, J. Modulating Macrophage Polarization through CCR2 Inhibition and Multivalent Engagement. Mol. Pharm. 2018, 15, 2721-2731. [CrossRef] [PubMed]

32. Perdiguero, E.; Sousa-Victor, P.; Ruiz-Bonilla, V.; Jardí, M.; Caelles, C.; Serrano, A.L.; Muñoz-Cánoves, P. p38/MKP-1-Regulated AKT Coordinates Macrophage Transitions and Resolution of Inflammation during Tissue Repair. J. Cell Biol. 2011, 195, 307-322. [CrossRef] [PubMed] 